\title{
A GÊNESE DA DIALÉTCA EM PLATÃO*
}

Jayme Paviani**

SINTESE - A Dialética de Platão, antes de alcançar os estágios dos processos diaíresis e da synagogê e de "intuir" o Bem, o Uno, passa pelo processo da refutção, elenchos, também conhecido como "diálogo socrático" presente nos primeiros Diálogos. Esta apredizagem da dialética articulase com duas origens: a dos argumentos de Zenão de Eléia e a das aporias de Heráclito.
ABSTRACT - In order to attain the stages of the process called diairesis and synagogê and the intuition of the Good, the One, Plato's dialectics requires the process of refutation, élenchos, known as "Socratic dialogue", which in the early Dialogues. This apprenticeship of dialetics is bound with the arguments of Zeno of Elea as well as with Heraclitus' aporiae.

Uma das origens da Dialética, indicada por Aristóteles, encontra-se nos argumentos de Zenão de Eléia, defensor de Parmênides. Contra a realidade concebida como devir, Parmênides afirma que o ser é e que é impossivel que não seja. O ser é imutável, eterno, ilimitado, perfeito e, por isso, não pode ser gerado ou destruído. A realidade ou natureza, physis, não oferece contradições. A percepção dos contrários é apenas uma falsa ilusão. A verdadeira imagem das coisas é a esfera, a realidade acabada e perfeita. Posicionado nesta concepção da physis, Zenão elabora seus argumentos contra o movimento e a multiplicidade. Os argumentos têm um caráter lógico-semântico e tendem a ser desenvolvidos numa linguagem formalizada. O paradoxal desta origem da Dialética é que ela se situa na área da lógica ou da lógica retórica. Isto talvez explique por que a Dialética é vista como um adjetivo que acompanha o substantivo arte, techne, ou capacidade, dynamis.

Platão fala da Dialética também como ciência, episteme. Ciência que pode empregar recursos lógicos ou analíticos em seus desenvolvimentos iniciais e parciais, mas que se constitui de modo autônomo como a ciência dos opostos, conservados e superados, pela Idéia final ou síntese de Bem ou Uno. Todavia, a visão aristotélica de Dialética, ligada a uma lógica "fraca" e próxima à retórica, aproxima-se, via os sofistas, ao diálogo socrático, ao discurso caracterizado como procedimento argumentativo, como processo de refutação, interrogação, elenchos. Nesta perspectiva, a influência dos argumentos de Zenão, certamente diluídos e descaracterizados em seus aspectos lógicos, marcam presença nos processos retóricos e, em conseqüência, no diálogo socrático. Tal dedução parece ter sentido quando se examina o

O presente estudo corresponde ao segundo capítulo, dos nove previstos, do ensaio A Dialética em Platão.

* Instituto de Filosofia e Ciência Humanas da PUCRS.

\begin{tabular}{|l|l|l|l|l|l|}
\hline VERITAS & Porto Alegre & v. 41 & $\mathrm{n}^{2} 164$ & Dezembro 1996 & p. 629-635 \\
\hline
\end{tabular}


esforço de Platão, no Fedro, e em outros diálogos, ao demonstrar a diferença entre a Dialética e a Retórica.

A passagem dos argumentos lógicos de Zenão para a constituição do discurso sofístico, retórico e conseqüentemente para a caracterização do diálogo socrático, pode se apresentar como uma hipótese válida capaz de explicar uma das origens da Dialética de Platão. Tal suposição exige naturalmente uma releitura dos textos filosóficos gregos, especialmente de Platão. A tese de Parmênides, afirmando que o Ser é e o Não-Ser não é, eliminando a oposição entre ambos e o Devir, indica, primeiro, que as oposições existentes na natureza, physis, são um problema e, segundo, que o modo de pensar de Parmênides não explica as contradições, as transformações e a multiplicidade dos entes. Tal posição, contraposta à de Heráclito, afirmando o Devir e as oposições na physis, introduzida na filosofia de Platão, constitui-se duplamente como uma oposição Dialética teórica e como uma lição de necessidade de busca de uma síntese, já tentada por algumas filosofias anteriores, para o problema natureza. O complexo de problemas filosóficos acumulados na época de Sócrates, examinados nos diálogos de Platão, apontam, ao mesmo tempo, o abandono dos argumentos lógicos em favor da elaboração dos processos dialéticos e, assim, como examinaremos adiante, apontam também uma segunda via para gênese da dialética, o Devir de Heráclito.

A oposição entre as duas teses, na filosofia de Platão, além da superação de ambas, implica a necessidade de busca de uma sintese, de uma unidade, para explicar a multiplicidade, sem a eliminar. A busca da unidade já havia sido tentada por diversos filósofos. Empédocles, por exemplo, ensina que o que nasce e morre tem sua unidade original no ser. A efetivação desta unidade através dos elementos básicos que são a água, a terra, o ar e o fogo, "raízes de todas as coisas", não se realiza através da superação dialética das oposições, mas através da mistura de elementos que originam distintas formas de realidade, physis, que são, ao mesmo tempo, eternas e mutáveis. Anaxágoras, por sua vez, aceita que o ser é único e permanente e que cada ente pode se tornar múltiplo, graças às homeomerias, isto é, às "sementes" que são partes iguais e pequenas de massa imperceptíveis. A descoberta mais importante de Anaxágoras, todavia, consiste na idéia de uma Inteligência ordenadora, Nous, na qual não existe nenhuma mistura. É esta Inteligência sutil, independente, ilimitada que conhece tudo e tem imensa força.

Estas e outras tentativas de solução do problema da unidade e da multiplicidade, sempre tendo presente o confronto entre as posições de Parmênides e Heráclito, e ainda o atomismo de Demócrito, podem ter posto em crise o valor do conhecimento para os sofistas, e ter influenciado suas posições relativistas, mas certamente forneceram para Platão a necessidade de uma síntese. Talvez de uma sintese dada a priori e, por isso, só alcançada no estágio de máximo desenvolvimento da Dialética, após superadas todas as explicações naturalistas. A Dialética é para Platão, por própria experiência, um longo aprendizado, um efetivo amadurecimento intelectual e emocional. Os sofistas são incapazes de perceber os processos presentes nas oposições e na necessidade de sintese da physis. Reduzem os opostos a problemas retóricos, de concordância e discordância, sem saber se as oposições estão nas coisas ou no conhecimento das coisas e de si mesmos, ou ainda em ambos. Por isso, Platão empreende a tarefa de superar a falsa retórica e de estabelecer 
as condições da verdadeira Dialética. Enquanto a Retórica é a arte dos discursos longos, continuados, expositivos, persuasivos, fundados em argumentos aparentes, a Dialética, ainda próxima da Retórica, define-se como diálogo específico, socráti$\mathrm{Co}$, arte da pergunta e da resposta, ou mais exatamente, processo de refutação. $\mathrm{O}$ diálogo socrático prepara o caminho da Dialética interpondo-se entre, de um lado, os processos erísticos, agonísticos, de disputas, dos eleatas e, de outro lado, os processos de reunião, synagogê, e de divisão, diaíresis. Superando os primeiros permite o desenvolvimento dos segundos. $\mathrm{O}$ diálogo procura o ponto de vista comum dos interlocutores. A Dialética tem como fundamento comum o Bem, o Uno, a Verdade.

Uma outra gênese da Dialética tem início no pensamento de Heráclito. Hegel chega mesmo a declarar que Heráclito é o fundador da Dialética. A origem que aponta os argumentos de Zenão como começo da Dialética influi, sem dúvida, na retórica sofística e no diálogo socrático. Porém, o ponto de partida em Heráclito desloca o problema em do enfoque lógico-lingüístico ou meramente retórico para o problema da constituição da realidade ou da natureza, da physis. O tudo flui, panta rei, supõe a realidade em estado de movimento, de permanente transformação. A physis não é Ser, também não é Não-Ser, mas tudo isto efetivado num terceiro estado, o Devir. Esta concepção, todavia, não é afirmada por Heráclito de um modo tão explícito. A explicitação pressupõe a leitura dos textos de Platão, vistos em conjunto, e interpretados a partir da Doutrina Não Escrita. De fato, Heráclito não esclarece a exigência de uma síntese. Ela está pressuposta. Em Platão, poder-se-ia dizer, está imposta. É imposta no sentido de que ela é dada a priori e pressuposta nas diversas tematizações dos diálogos. Demonstrações da necessidade da sintese em Platão encontram-se, por exemplo, em Carlos Cirne Lima, em Dialética para principiantes.

Pode-se sublinhar no pensamento de Heráclito dois aspectos: a) a realidade em movimento como algo definitivo para a Dialética e b) a oposição entre Ser e Não-Ser que se efetiva como Devir. Esta concepção apresenta os elementos fundamentais da dialética hegeliana e constitui um dos problemas básicos da dialética platônica. Mais do que isto, a posição relativa às oposições da physis, ou tentando eliminar os opostos, reduzindo em grande parte o problema ao nível lingüístico, como fez Aristóteles, ou tentando entender e explicar os movimentos da physis num nível de superação das contradições a partir de princípios unificadores, sem eliminar os opostos, como fez Platão, dividem a História da Filosofia em duas grandes linhas de pensamento. Entretanto, esta divisão tem um sentido e o sentido reside nas razões que a provocaram. Paradoxalmente Parmênides e Heráclito apontados como os pontos de partida desencadeadores da origem da Dialética, com suas posições reais e emblemáticas, são também, depois de dois milênios de Filosofia, a possibilidade de entrelaçamento do pensamento dialético e analítico. A tese de Cirne Lima de que dialéticos e analíticos podem se entender, e de que não existe um método filosófico puro que não necessite de outro em seu desenvolvimento, pode ser articulada com os problemas que constituem a gênese da Dialética e da Analítica.

O exame processual do diálogo socrático constitui uma espécie de filtro usado por Platão, na aprendizagem do filósofo, para alcançar o estágio do pensamento 
dialético. A passagem do diálogo socrático para a dialética vista como reunião, synagogê, e divisão, diairesis, pode ser reexaminada de diversas maneiras nos diálogos platônicos. São ilustrativas, por exemplo, as referências típicas de uma autobiografia intelectual de Platão, no Fedon (a partir de 96 b), onde descreve como o "problema da física" se transforma em "problema dos opostos e das Idéias". Ele abandona as explicações pelas causas naturalistas (fogo, água, terra, etc.) e mesmo intelectualistas (Inteligência superior) adotando um novo modo de pensar. Neste sentido, Platão visto em geral como um filósofo dualista, sempre enredado em aporias, praticando uma espécie de dialética negativa, pode ser visto, através da Teoria das Idéias e dos Princípios do Uno e da Díade, que Aristóteles não aceitou, como um filósofo que pratica uma Dialética plena.

Em sua juventude, narra Platão, sentiu-se apaixonado pelo gênero de estudo a que dão o nome de "exame da natureza". Parecia-lhe admirável conhecer as causas de tudo, saber por que tudo existe, por que nasce e morre (Fedon, $96 \mathrm{a}, \mathrm{b}$ ). Descobre que a origem, o fundamento, o arkhé, de todas as coisas não se encontra nos elementos como a água, o fogo, os números... Após estudar o "problema da physis" está longe de saber a causa de qualquer coisa. O máximo de explicação que encontra é a existência de uma unidade que origina os opostos e não que os suplante. Por isso, escolhe um outro método. No se trata ainda do método dialético em seu mais alto grau. Mas é um passo decisivo. Conta que ouviu alguém ler num livro de Anaxágoras que a Inteligência, o Espírito, Nous, é o ordenador e a causa de todas as coisas. Num primeiro momento, tal descoberta causa-lhe alegria, e parece-lhe que havia, sob certo aspecto, vantagem em considerar a Inteligência, o Nous, como causa universal (Fedon, 97 c). Todavia, a leitura de Anaxágoras não lhe fornece explicação satisfatória. Confessa, então, que abandona todas as causas sensíveis ou ligadas às explicações sensiveis e opta por uma "segunda excursão" capaz de fornecer uma é explicação de nível inteligível do "problema da physis" (Fedon, 99 d). Esta "segunda navegação", segundo Giovanni Reale, simboliza na linguagem dos marinheiros que cessando o vento e não mais sendo possivel avançar com as velas, torna-se agora necessário avançar com os remos, isto é, com o esforço próprio. A metáfora representa para Platão a necessidade de uma nova tentativa, diferente daquelas dos autores pré-socráticos, para solucionar o problema dos opostos e da multiplicidade da natureza. Platão afirma que tem medo de tornar-se cego olhando as coisas com os olhos e captando-as com os sentidos. Por isso, busca refúgio nas idéias (logoi) e procura nelas a verdade das coisas (Fedon, 100 a). Convence-se que há um bom em si, um belo em si, um grande em si e assim por diante e o que faz alguma coisa ser bela ou grande é o belo em si e o grande em si. Embora não explique como se realiza essa participação, essa relação entre as idéias e as coisas sensiveis e a relação entre as idéias entre si, Platão procura encontrar uma solução para o problema, além de uma explicação analítica, lingüística, lógica. Não se trata apenas de formas ou modelos, as idéias são entidades, com características próprias, mas, de um certo modo não explicitado satisfatoriamente por Platão, presentes nas coisas sensiveis. Independente desta explicação, interessa no momento perceber como o pensamento dialético pressupõe a busca de uma síntese para as contradições da realidade. 
Depois de admitir "as realidades inteligiveis" como "causas verdadeiras", Platão evoca o princípio, arkhé, ou postulado, hypothesis, que fundamenta a teoria das Idéias. Os Princípios, ensinados na Doutrina Não Escrita, aceitos pelos verdadeiros filósofos, explicam os seres, como uma coisa se forma ou não de coisa contrária.

A leitura do Fedon chama atenção sobre o itinerário intelectual de Platão e serve concomitantemente para mostrar que o diálogo socrático não é apenas um exercício formal, um recurso externo e arbitrário. Processa-se no próprio diálogo 0 desenvolvimento dos problemas abordados. A opinião corrente de que a dialética platônica muda conforme as características dos diálogos precisa ser revista. Na realidade, existem períodos que caracterizam os escritos de Platão. Se são dois ou três, segundo os estudos dos comentaristas, não é o caso agora de examinar. Há uma certa concordância de que os diáiogos da juventude e do início da maturidade, em torno de problemas socráticos e éticos, a dialética procede por refutação, interrogação, elenchos; e que nos diálogos da maturidade avançada e nos últimos, em torno de problemas metafísicos, desenvolve-se uma dialética configurada pelos processos de reunião e divisão, synagogê e diaíresis. Se estes diferentes momentos podem ser justificados, embora com critérios não tão rígidos, é possivel demonstrar que o chamado diálogo socrático está na origem constitutiva da dialética de Platão.

O diálogo socrático desenvolve-se por refutação ou interrogação (pergunta e resposta), nos diálogos juvenis, predominantemente investigando uma determinada tese. Os diálogos da maturidade o processo por refutação, elenchos, confronta teses opostas. Esta maneira de ver a dialética dos diálogos juvenis e do início da maturidade, tendência dominante entre os comentaristas, é questionada por Cristina Rossitto, pois, segundo ela, estes procedimentos próprios do điálogo socrático encontram ainda presentes nos últimos diálogos de Platão, nos diálogos chamados dialéticos, que procedem por divisão, diairesis, em duas ou mais parte e por reunificação, synagogê, de diversas partes numa única (1995, p. 39 a 57). No Sofista, por exemplo, onde se teoriza pela primeira vez a Dialética como synagogê e diaíresis, não se abandona totalmente o procedimento por elenchos. A Dialética diairética entra em ação a partir dos resultados conseguidos pela dialética interrogadora de estilo socrático. Rossitto argumenta indicando a passagem onde o Estrangeiro afirma que abandonar essas argúcias próprias aos novatos, e que não envolvem dificuldade alguma, e mostrar-se capaz de seguir a marcha de uma argumentação, criticando-a passo a passo, e, quer ela firme ser o mesmo sob uma certa relação o que é o outro, ou outro o que é mesmo, discutí-la de acordo com a própria relação e o ponto de vista que ela considera em uma outra assertiva, é ainda insatisfatório sob o ponto de vista dialético. Platão continua ainda dizendo que mostrar não importa como, que o mesmo é outro, e o outro, o mesmo; o grande, pequeno; o semelhante, dessemelhante, sentindo prazer em apresentar perpetuamente essas oposições nos argumentos, isso não constitui a verdadeira crítica: é apenas, evidentemente, o fruto prematuro de um primeiro contato com o real (Sofista, 259, c, e). Esta citação mostra com clareza que não há um salto entre o método dos diálogos socráticos e o método dos diálogos dialéticos, apesar de uma divisão dos diálogos em períodos com características predominantes. O predomínio não significa eliminação das características secundárias. Pode-se concluir, igualmente, que a 
Dialética praticada exemplarmente no Sofista, no Parmênides, e em outros diálogos da última fase, não exclui absolutamente o recurso analítico.

Para aprofundar a questão talvez seja oportuno examinar a tendência da História da Filosofia de ontologizar a pergunta socrática "o que é". A interpretação que insiste na centralização da pergunta em torno da essência de algo, em busca do universal, relega a um plano inferior os demais elementos da pergunta, a relação, por exemplo, entre os interlocutores no exame do problema. Com os estudos atuais da Pragmática e da Semântica talvez seja possivel investigar os aspectos lingüísticos do diálogo socrático. Afinal, uma pergunta requer uma resposta e como tal supõe um encadeamento que provoca sempre novas perguntas com outras respostas. O movimento da indagação pode coincidir ou não com o que é perguntado. $O$ modo de perguntar pode determinar o que é indagado. A pergunta socrática pode ser interpretada não apenas como a busca da essência de algo, do eidos, do universal, mas como uma questão que visa o esclarecimento do que é dito no diálogo. Nesse caso, como lembra Gabriele Giannantoni, "o que é" significa "o que dizes" ou "o que queres dizer" com tais palavras (1995, p. 5). Não se trata então de definir conceitualmente algo, mas de saber o que o interlocutor quer dizer. Nesta perspectiva, o dialogar é uma forma de meditar, de refletir sobre uma série de problemas comuns aos debates da época e que precisavam ser melhor situados. Mas, para Platão, a solução parece não estar no diálogo, pois ele não tem condições de alcançar verdadeiramente a Verdade. O diálogo, devido às dificuldades do consenso, acaba em aporias. Ele precisa de uma norma, de um critério, para progredir. Por isso, a pergunta socrática, é vista como "o que é" (ontológica) ou "o que dizes" (semântica), ocupa uma posição subalterna em relação à contemplação dialética. Dito de outro modo, por refutação, elenchos, é possível progredir, porém, só se alcança - Bem, o Uno, através da Dialética. E é exatamente a contemplação do Bem, do Uno, da Verdade que possibilita o diálogo.

As conexões entre os aspectos lingüísticos e ético-ontológicos estruturam o diálogo socrático. Sócrates para obter respostas às perguntas procede por refutação. No entanto, a refutação socrática é diferente da argumentação dos sofistas. Esta é manifestamente um discurso persuasivo, aquela um discurso de convencimento. Em outras palavras, os sofistas não pretendem resolver as contradições, os opostos, não sabem explicar a multiplicidade, seja da natureza ou da conduta moral. Tomam partido frente aos problemas conduzidos por interesses pessoais. Movimentam-se apenas no círculo das opiniões, da doxa. Ao contrário, Sócrates conduz o diálogo refutativo à superação das opiniões, através da investigação da verdade. Sócrates age como se ainda não tivesse alcançado a verdade, por isso, assume o procedimento metódico da descoberta, o processo maiêutico, sempre supondo a existência da verdade, isto é, uma síntese, uma unidade, princípios capazes de explicar a realidade. Quando o diálogo socrático não toma posição, como no Crátilo, é evidente a tendência de não eliminar os opostos e o esforço de busca de uma síntese que reconstrua os opostos num outro nível. Assim, a inconclusão dos diálogos socráticos não é um defeito, mas a indicação clara de que ainda não se alcançou a plenitude do pensamento dialético.

O procedimento refutativo, interrogativo do diálogo socrático não é apto a resolver as questões já postas pelas filosofias de Heráclito e Parmênides, agravadas 
por outros filósofos e sofistas. Por isso, a dialética de Platão substitui esses procedimentos propedêuticos, sem os eliminar, e assume os procedimentos diairéticos. Neste sentido, torna-se necessário examinar os processos dialéticos dos últimos diálogos e especialmente do Sofista e do Parmênides.

\section{Referências bibliográficas}

CIRNE LIMA, C. R. V. Dialética para principiantes. Porto Alegre: EDIPUCRS, 1996.

GADAMER, H. G. La dialética de Hegel. Madrid: Catedra, 1988.

GIANNANTONI, Piero di. Il dialogare socratico e la genesi della dialetica platonica. In: Platone e la dialetica, a cura de P. di Giovanni. Roma-Bari: Laterza \& Figli, 1995.

KRÄMER, H. Dialetica e definizione del bene. Trad. de Enrico Peroli, introduzione di Giovanni Reale. Milano: Vita e Pensiero, 1989.

PLATON. Oeuvres complètes, t. IV. Phédon. Texte établi et traduit par Léon Robin. Paris: Belles Lettres, 1967.

PLATON. Oeuvres complètes, t. VIII, Le Sophiste. Texte établi et traduit par A. Diès. Paris: Belles Lettres, 1963.

CORNFORD, F. M. Plato's theory of knowledge. The Theaetetus and the Sophist. Translated with a Running Commentary by F. M. C. London, 1964.

MOVIA, G. Apparenza, esse e verità, commentario storico filosofico al "Sofista" di Platone. Milano: Vita e Pensiero, 1991.

ROSSITTO, Cristina. La dialetica platonica nel Sofista: Elenchos o diaresis. In: Platone e la Dialética. Roma-Bari: Laterza \& Figli, 1995. 